\title{
A conversation with Marc Feldmann, Jacques Miller, and Max Cooper
}

$\mathbf{T}$ month, we shift our format to listen in on the conversation of three legends of immunology. Sir Marc Feldmann, Lasker awardee in 2003 for his role in discovering anti-TNF therapy, acts as interviewer, speaking with the two winners of the 2019 Albert Lasker Basic Medical Research Award: Max D. Cooper from Emory University and Jacques Miller from the Walter and Eliza Hall Institute of Medical Research (WEHI). Drs. Miller and Cooper (Figure 1) identified and defined the function of $\mathrm{T}$ and B cells, uncovering the organizing principle of the adaptive immune system. The full interview can be seen on the JCI website at https:// www.jci.org/videos/cgms.

Feldmann: Thank you for this opportunity to take part in this conversation with two of my friends and heroes. We're now three of the elder statesmen in immunology and it's a privilege to be back together. I first met Jacques the week I started my PhD at the WEHI 50 years ago, and Max a few years later, during my first postdoc in London, as he came for a sabbatical. Can we start at the beginning - perhaps tell us where you grew up?

Miller: I grew up partly in China, partly in Switzerland, and back to China, and then to Australia. My sister had contracted tuberculosis, and Switzerland was the place where people said you could manage tuberculosis before streptomycin. We had to leave Switzerland because of the German invasion of France and we thought that the Germans would go through Switzerland. So we went back to China and stayed for two years before the Japanese war started, then we left China again, this time for Australia.

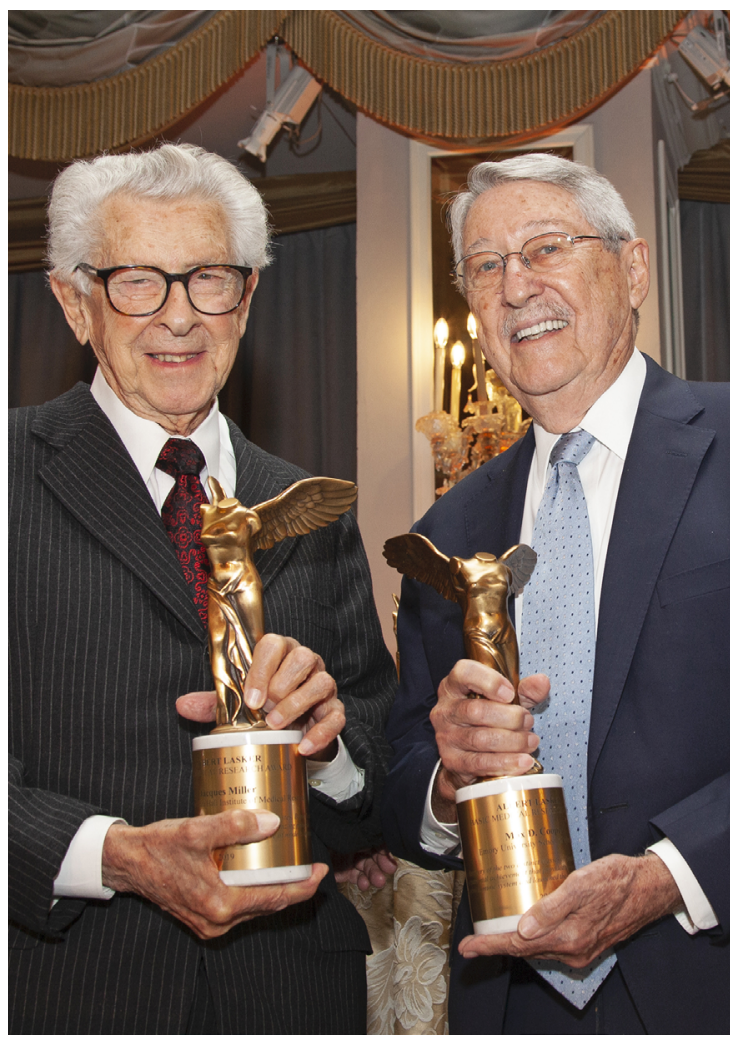

Figure 1. Jacques Miller and Max Cooper receiving the 2019 Albert Lasker Basic Medical Research Award in New York City on September 20, 2019.

My parents had no knowledge of medicine. My father was a manager of the Franco-Chinese Bank and he was a very learned person. He spoke Japanese, three Chinese dialects, German, English, and French. He was very pleased when I decided to go into medicine. I grew up in a very nice, familial atmosphere.

Cooper: I grew up in rural Mississippi. I lived on a school campus as my father was the superintendent of a 12-grade school. My mother was a teacher as well. My father was a mathematician who loved learning. He made sure that there were lots and lots of books in the school and in our home. It was a little bit like being the preacher's son, to be the super- intendent's son. I had my full quota of mischievousness along with getting instilled with a set of principles and a love for learning and reading that have made an immense difference in my life. One of my teachers in high school once told me, "Max, if you hadn't had the parents you have, I think you would have ended up in jail."

Feldmann: You both did your pioneering work in basic science, in immunology. But you both started in medicine. Why did you decide to study medicine rather than go into science?

Miller: I was heavily influenced by my sister's tuberculosis, and the fact that my other sister and I used to play with her and we never got it. I overheard my mother talking to the doctor, who told her, "We don't know anything about tuberculosis. Hard stuff." That spurred my curiosity. I wanted to go to medicine partly for that, and partly for the fact that I was brought up during World War II and people were killing each other and I didn't want to kill anybody. I thought I'd better study medicine, so I could patch them up rather than kill them.

Once I studied medicine, I became even more curious because I saw diseases like leukemia and systemic lupus erythematous and wanted to know why people got disease. That spurred my curiosity toward medical research.

Cooper: The general practitioner in my small rural town in Mississippi was one of the most treasured people in the community. My father came from a large farm family, had the ambitions to be a doctor, but didn't have the finances. They both encouraged my early interest. As I learned about sports and girls and how long and hard I would have to study to become a doctor, my ambition waned a bit. Unfortunately, my older brother, who was in the Marines, was killed in a car accident when he was home on leave before going to Korea. We 
were very close and he had named me as the beneficiary of his insurance policy. That took away my excuse of the financial aspects of becoming a physician.

It was such a lucky break for me to go into medicine. It got more interesting as I learned more about physiology and diseases. My particular interest in immunology came when I had decided on an academic career through the encouragement of my pediatrics chief at Tulane. By that time, I was very interested in immune deficiency diseases and allergy.

Before beginning my immunology and allergy fellowship, I was asked to learn an immunofluorescence technique to study delayed-type hypersensitivity. An immunologist in England took me into his lab to teach me the technique and he was baffled by my answer when he asked what I was going to do with the technique, saying, "As far as I know, this immunofluorescence technique is only useful for studying antibody production, not cellular immunity." I was so embarrassed that I decided I was going to learn, if nothing else, the difference between cellular and humoral immunity. I retreated to the library. I found a book by the previous director of the WEHI, Sir Frank MacFarlane Burnet, on clonal selection theory. It was written so well and in such an understandable fashion that I just fell in love with immunology.

Feldmann: The love affair was reciprocated. Another theme I'd like to discuss is the role of personal insight versus the role of supervision. Were you actually supervised when you were a trainee, or did you come upon your findings via your own innate insights?

Cooper: When I joined Bob Good's group in Minneapolis, I asked what I should do. He said, "When I went to Rockefeller, Maclyn McCarty didn't tell me what to do. In fact, he left for a European holiday." I was directed to start working on the ideas I mentioned during my interview. I quickly exhausted those ideas without making any great discoveries.

Miller: When I first arrived in Pollards Wood for scientific research in the UK, I was supposed to be supervised by Robert Harris, but within a few weeks he left, as he was given a much better job at National Institutes for Medical Research. I was left without a supervisor, but I was able to inherit his animal space, which was very important because I was going to use a lot of mice. After having read what people did with mouse leukemia, I thought I could do similar work in virus-induced leukemia. I did not realize that this path would take me to immunology. It seemed to work very well for me that I didn't have a supervisor.

Feldmann: Jacques, I remember that in my first year as a student I visited you in the animal room, I saw you do a neonatal thymectomy with your technician, and I was hardly able to see the operation on the tiny mice. Most people would not have thought, when they realize that a neonatal mouse is smaller than a fingernail, that this operation would have been possible.

Miller: In the work on leukemia, I had to thymectomize adult mice. I developed a technique that might have been unique because I used to take out part of the sternum knowing that the mouse would repair that - they repair very easily. I decided to adopt this technique in neonatal mice. With my eyes at the time I could see what I was doing and a slight suction - very slight - in the newborn mouse would do the job to remove the thymus completely. In fact, neonatal thymectomy was easier than adult thymectomy because the adult animals got pneumothorax very easily, but the newborns did not.

Feldmann: Can you take us back even further to explain how you discovered that the thymus was an immunological organ, when everybody else thought it was just a relic?

Miller: Everyone said it was a useless organ, a graveyard for dying lymphocytes. I was working on mouse leukemia, which begins in the thymus and spreads. Mouse leukemia can be induced by virus, and at that time the virus had to be given to newborn mice. I decided to investigate whether the virus could multiply outside the thymus. I took the thymus out of newborn mice, then gave the virus, and then grafted the thymus back later to see whether the virus had multiplied in the absence of thymic tissue. As a result of this work, I noticed that mice thymectomized at birth were very sick after about 3 or 4 months, but I never saw sickness in adult thymectomized mice. In post-mortems I noted they lacked lymphocytes and had lesions in the liver, which suggested they had been infected by hepatitis virus, which is endemic in mouse colonies but usually doesn't bother them.
There was something wrong with their immune system, and I tested by grafting these mice before they were sick with foreign grafts from different strains of mice and even from rats, and to my amazement, they did not reject the grafts.

Feldmann: These were very striking findings that underpin much of modern immunology. Max, you're credited with discovering the function of the bursa. Can you take us through how these discoveries were made?

Cooper: I started out with an interest in infections of patients, and in particular, children who were congenitally unable to handle infections, those either having multiple bacterial infections, pneumonia, ear infections, or viral infections which were often fatal. I joined Bob Good's group, who had an interest in immunodeficiency diseases and how the immune system developed and what could go wrong. There had been published a fortuitous discovery by an Ohio State poultry scientist, who found impaired development of antibody responses on removing the bursa of Fabricius, a lymphoid organ at the end of the gut that was sometimes called "the cloacal thymus." He started with the idea that it was affecting development and sexual maturation. It didn't affect either of those, but a postdoc came by, asked for some of his birds for an antibody demonstration and made the discovery that there were none.

That work and Jacques' findings made us realize that it was particularly important to go back early to look at the thymus and this second organ. We did experiments spurred by observations in immune-deficient children where the thymus and the small lymphocytes hadn't developed well, but they still had plasma cells, and made lots of immunoglobulins and antibodies. In order to test whether the thymus and the bursa were complementary or doing different things, we realized we needed to remove them earlier or reset the immunological clock. We did the latter by exposing newly-hatched chicks to almost lethal irradiation together with removal of the thymus or the bursa of Fabricius.

When they grew up and recovered from the irradiation effects, we found absolutely clear-cut results that indicated that the thymus gave rise to lymphocytes that were responsible for graft rejection and other cellular immune functions. The 
bursa of Fabricius was instead essential for development of germinal centers, plasma cells, and antibody production, and we could put back the bursal cells that weren't irradiated and restore in bursectomized and irradiated animals the whole $\mathrm{B}$ lineage, or bursa-dependent lineage.

Feldmann: With hindsight, it's so clear that the principles that you uncovered are true in mammals and birds have really fundamental importance. As I recall, the work that you did, Jacques and Max, was not initially that highly appreciated.

Miller: When you say it wasn't appreciated, I think one should say the data were accepted; you could not possibly talk against the data when you see a mouse with four different skin grafts of different colors and even a rat skin graft. You can't argue against the data, but you can argue against the interpretation.

My interpretation was that the immune system develops as a result of early thymus function, and their interpretation was that my mice, having been raised in converted horse stables, were so prone to infections that the additional trauma of thymectomy or irradiation and thymectomy in the adult would precipitate immunodeficiency. That's what led me to go to NIH courtesy of an Eleanor Roosevelt Fellowship to repeat the entire work in germ-free tanks. These mice could not be infected because they were germ-free. We put skin grafts on them after thymectomizing in early life and the skin grafts were never rejected even if they were highly disparate at the major $\mathrm{H} 2$ locus. I think that convinced most immunologists that the thymus must have some function.

Cooper: Clinicians were a little more accepting than basic immunologists particularly because at that time, there was not a wide appreciation of an evolutionary approach to understanding the immune system. I don't think Jacques and I ever doubted the importance of what we found. It was just a question of how to answer some of the questions that our new view asked. If $\mathrm{T}$ cells, or thymusdependent lymphocytes, didn't make antibodies, how did they see antigens? Where in the world was an equivalent site for generating B cells that were needed to make antibodies in mammals like us? And how did the cooperation actually occur? Or were there functional interac- tions between thymus-dependent cells and bursa-dependent cells, which were quickly renamed to $\mathrm{T}$ and $\mathrm{B}$ cells?

Feldmann: Soon after he retired, MacFarlane Burnet published in the Cold Spring Harbor Proceedings quite a pessimistic view of the future of immunology, thinking that most great discoveries were already made, and future scientists would simply argue over minutiae. Are you more sanguine? Where will we be 50 years from now?

Miller: I think immunology has a great future. We need to produce antibodies that are long-lasting and specific in order to improve vaccination and therefore we need to work out details about interactions between follicular T helper cell and B cells. We need to work out all the details of the interaction at the molecular level, at the level of lymphokines, and see whether we can improve such interactions. We need to find vaccines for malaria, for HIV, for influenza. We should be able to activate $\mathrm{T}$ cells that are specific for the internal peptide of the influenza virus, so that we could have a response that is specific for all influenza strains.

The interaction between the microbiome and the immune system is also very important in order for us to understand what goes on in disorders like inflammatory bowel disease. The innate immune system needs to be looked at very carefully because gamma delta cells are very common in the intestine and we're not quite sure what they do, again for example, in inflammatory bowel disease. We know that they produce inflammatory response but what do they actually respond to in a way which could cure? The interaction between $\mathrm{T}$ cells and cancer cells is also important because we need to understand why not all cancers can be cured by targeting T cells. So yes, there's tons of things to do in immunology.

Feldmann: Max, I'd like to ask you the same question, but also can you tell us a little about your latest project on evolutionary immunology, exploring immune molecules in lampreys and hagfish which I was stunned to read about some years ago.

Cooper: To build on Jacques's more specific answer, until we know enough about how the immune system develops and functions and about all of the cells that the immune system interacts with, we won't be able to fully understand diseases like cancer, autoimmune disease, degenerative disease, or inflammatory diseases that destroy every organ. We're not even close yet, we have a long way to go.

As to your other question, everything has to be understood in an evolutionary sense to provide meaningful answers in biology. Our relatively recent activities toward understanding how our adaptive immune system evolved meant going to jawless vertebrates - lampreys and hagfish - because all of the surviving jawed vertebrates have $\mathrm{T}$ and $\mathrm{B}$ cells that use immunoglobulin-based receptors to recognize antigens and the same basic histocompatibility system.

We've found that the jawless vertebrates also have T-like and B-like cells, but they use different kinds of building blocks - leucine-rich repeats or LRRs - to construct their diverse antigen receptors and antibodies. We think the lamprey antibodies, particularly because of their remarkable antigen specificity and evolutionary distance from us, will allow their use for diagnostic purposes and perhaps even for therapy of malignancies by identifying novel tumor antigens. We have early proof of principle data on that, but still have a long way to go to reach both goals.

Feldmann: What other paths might you have found interesting if not for immunology and medicine?

Miller: I would have gone into astronomy, but at that time there were no satellites, nothing like that. I didn't want to end up teaching physics in a school. I thought I needed something exciting and that next best thing was medicine.

Cooper: I started college on a football scholarship as a quarterback. It turned out I was the least capable quarterback and the slowest man on the team, including the coaches. It was clear that I was never going to gain fame and fortune as an athlete. I loved to sing and I loved music. My secret ambition if I could have gone back and recreated my life, I would have been a saxophone player.

\section{Marc Feldmann, Kennedy Institute of Rheumatology, University of Oxford}

Ushma S. Neill, JCI Editor at Large 